\title{
SOUNDS OF SILENCE: ORgANISATIONAL TRUST AND DECISIONS TO BLOW THE WHISTLE
}

\author{
ELLI BINIKOS \\ Department of Sociology \\ University of Johannesburg \\ South Africa \\ Correspondence to: Elli Binikos \\ e-mail: ebinikos@uj.ac.za
}

\begin{abstract}
Whistleblowing is a form of pro-social behaviour that occurs when an employee reports organisational wrongdoing to an authority able to implement corrective action. While a number of social factors may influence an employee's decision to blow the whistle, very little cognisance is given to the role of organisational trust. Since whistleblowing situations often pose problems for whistleblowers, organisational trust becomes an important facilitator for the decision to blow the whistle. Drawing on a case study, this paper shows that when trust exists, employees are more likely to blow the whistle and to do so internally rather than externally.
\end{abstract}

Keywords: whistleblowing, public disclosure, victimisation, hostility, decision-making, trust

Courageous efforts of whistleblowers to save organisations from corrupt internal practices are often met with harsh retaliation (Camerer, 1996; Miceli \& Near, 1992; Rothschild \& Miethe, 1994; Uys, 2000b). Although the organisations, industries and contexts in which whistleblowing has occurred are dissimilar, the responses of victimisation, hostility and general lack of appreciation are consistently similar in South Africa, as in much of the world.

The form retaliation takes and the consequences of such actions have been the focus of many research studies (Camerer, 1996; Miceli \& Near, 1992; Rothschild \& Miethe, 1994; Uys, 2000b). Within the literature, organisational retaliation is narrowly seen as a counterproductive means to avoid wrongdoing from being uncovered (Uys, 2000b, p. 265). The more severe the victimisation becomes, the greater the chances of further destructive outcomes for both the whistleblower and the organisation (Miceli \& Near, 1992).

Retaliation, however, has a further consequence that is seldom considered: The potential occurrence of future whistleblowing is seriously compromised when oppressive reprisals become evident. If organisations retaliate towards whistleblowers, not only is the whistleblower victimised and opportunities to address wrongdoing lost, but, importantly, trust in the relationship between the organisation and its employees is affected. Witnessing hostile and recriminatory treatment of an employee may have the effect of making other employees feel unsafe within that environment. Future actions of employees are impacted upon, and any behaviour that is considered risky may be avoided. The implication that this has for potential whistleblowing is that distrust may result in a disincentive to report future cases of wrongdoing.

This paper conveys the results of a study that explores the role played by trust in the organisation ${ }^{1}$ (organisational trust) in the extent to which employees would disclose information about wrongdoing, or rather choose to keep quiet. It also seeks to explore whether trust would encourage whistleblowers to disclose organisational wrongdoing internally rather than externally. It is argued that internal whistleblowing as the first point of the reporting process brings about the greatest opportunity for corrective action and the least consequence for the whistleblower - and the organisation. Therefore, relationships of trust aimed at promoting internal whistleblowing should be pursued. However, the concept of trust has not been adequately developed in order to understand whistleblowing. The research indicates that this may constitute a gap in the literature and that trust does indeed correlate interestingly with some forms of whistleblowing.

\section{Problem statement}

Retaliation against whistleblowers typically occurs when organisations have something to hide, when allegations are serious, and/or when dire consequences exist for the organisation as a whole, or for many within the organisation. Because of these implications, whistleblowers are given derogatory labels such as "rat" or traitor (Camerer, 1996, p. 48; Miceli \& Near, 1992, p.1; Uys, 2000b, p. 259), are considered to be dissenters (Miceli \& Near, 1992, p. 16), are viewed as disloyal to the organisation and become recipients of harsh, negative treatment (Uys, 2000b, p.32). Contrary to the organisation's expectation, retaliation affects the course of reporting, bringing about greater consequence for all involved. It inadvertently drives the whistleblower to seek alternative channels "as the reprisals confirm to the whistleblower just how morally bankrupt and lacking in integrity their superiors are" (Rothschild \& Miethe, 1994, p. 266). Furthermore, retaliation "serves to strengthen their [whistleblowers'] convictions about the rightness of their cause and to escalate the conflict to a level and duration they may never have anticipated or intended" (Rothschild \& Miethe, 1994, p. 269). As whistleblowers' actions persist and escalate, reactions become more aggressive. Miceli and Near (1992, p. 80), citing Shepherd (1987), say, "[r] etaliation may recur in a series of events and it may escalate if the desired outcome of discouraging the whistleblower is not accomplished". Repressive responses to reporting are therefore severely counterproductive for the parties involved. As Milliken, Morrison and Hewlin (2003, p. 1454) state:

Employees are often reluctant to share information that could be interpreted as negative or threatening to those above them in the organisational hierarchy ... This reluctance to speak up, and the silence or information withholding it gives rise to, has the potential to undermine organisational decision making and error-correction and to damage employee trust and morale.

What Milliken et al. (2003) point to is that if organisations retaliate against whistleblowers, then not only is the opportunity 
to address the wrongdoing lost but, in addition, trust in the relationship between the organisation and the whistleblower is broken and employee morale is harmed. The suggestion is made that trust plays a role in employees' decisions to report wrongdoing. For, if trust is harmed, it may result in the whistleblower being discouraged to report irregularities by keeping quiet or perhaps pursuing external channels.

On the other hand, Milliken et al. (2003) do not explore whether, if the whistleblower trusts the organisation, the option of remaining silent is reduced. Furthermore, since reporting to an authority within the organisation offers the greatest opportunity for constructive correctional action and ideally the least harm to the whistleblower, the question is raised: Would trust encourage internal whistleblowing? Could the effectiveness of whistleblowing as a corruption-fighting mechanism be increased through internal reporting built on relationships of trust? Trust may be critical to understanding whistleblowing choices and therefore deserves more academic attention than it has received.

\section{Purpose of the study}

This study is concerned with minimising the negative consequences of reporting for the whistleblower and with evaluating the intended prosocial benefits of such action. Rather than, as in some studies, focusing on the characteristics of the whistleblower, the organisation or the wrongdoing, this study focuses on the dynamics of the relationship between the organisation and the individual. Within the dynamics of interaction, it considers the transition from trust to distrust and how it may be prevented. While it is difficult to conclusively answer all these questions, the study may contribute towards an understanding by firstly investigating the role that trust plays in whistleblowing. To this end, the primary objectives are to

- establish whethera relationshipexistsbetween organisational trust and whistleblowing;

- establish whether employee silence is negatively influenced by organisational trust

- establish whether internal whistleblowing is positively influenced by organisational trust;

- establish whether external whistleblowing is negatively influenced by organisational trust.

\section{Defining whistleblowing}

The various definitions of whistleblowing largely cohere and are captured in the following formulation: Whistleblowing is the unauthorised disclosure of information about perceived organisational wrongdoing, by a member or former member of the organisation, to parties that are in a position to take action, where this disclosure is in the public interest (Camerer, 1996; King, 1999; Miceli \& Near, 1992; Uys, 2000b). Four aspects of the definition, as supported in the literature, are discussed, namely, whether whistleblowing is unauthorised, the nature of disclosure (internal or external), the type of wrongdoing and the intended benefits.

Typically, whistleblowing is considered to be the unauthorised disclosure of information whereby whistleblowers report along channels that are not specified for such information (Uys \& Senekal, 2005). In the first instance, Uys (2005) finds that the manner in which the disclosure is made may be considered unauthorised by the organisation. Because of the organisational response experienced, or because of the nature of the organisational wrongdoing itself, whistleblowers often have no choice but to proceed along lines of reporting that may be considered controversial or unauthorised. Furthermore, if channels for reporting are absent, the whistleblower may also proceed along lines that may be considered inappropriate by the organisation (Uys, 2005). Both these factors may lead to unauthorised disclosure when a whistleblower is forced to report 'over one's head', pursue unconventional internal channels or go to external regulatory bodies and the media in order to seek an effective solution to the problem ${ }^{2}$.

Extending from the point above is the idea that neither internal nor external disclosure is authorised when whistleblowing has occurred (Uys, 2005, p. 7). Although some may feel that internal reporting implies authorised action, this is not necessarily correct. It has already been shown that the perception of disclosure being unauthorised does not depend on whether it was internal or external, but rather has arisen merely because of the fact of disclosure itself (Uys, 2005, p. 7). It is therefore conceivable that the perception of a disclosure being unauthorised may occur at any stage of disclosure, albeit internal or external. As Uys (2005, p. 7) states, "[i]t is precisely the unauthorised nature of the whistleblower's disclosure that exposes him/her to the accusation of treachery".

In terms of defining internal and external whistleblowing, it can be said that internal whistleblowing refers to reporting to people or managers internal to the organisation that are in higher positions in the organisational structure. Internalcomplaint recipients may be direct-line managers, human resource representatives, CEOs, members of an executive council or board of directors. Internal whistleblowing may take place using both existing communication channels such as hotlines (Johnson \& Wright, 2004) or unexpected communication channels, if this is the only option remaining (Dehn, 2001). External whistleblowing refers to the disclosure of information to bodies outside the organisation, such as the media, politicians, ombudsmen, government bodies, regulatory bodies, public interest groups and enforcement agencies (Miceli \& Near, 1992).

Organisational wrongdoing is seen to include any illegal, unethical or harmful practices (Miceli \& Near, 1992) within the context of a particular organisation of which the whistleblower is a part. Wrongdoing may be constituted of "criminal activity, a contravention of any statute, improper or unauthorised use of public and other funds, miscarriage of justice, the abuse of power, maladministration..." (Uys, 2000b, p. 259; Uys \& Senekal, 2005 , p. 5). Typically, there are two categories of wrongdoing described in the literature:

Firstly, there is the wrongdoing that Miceli and Near (1992, p. 171) identify as organisational crime ${ }^{3}$, which are crimes "committed on behalf of an organisation by one or more of its employees, with the primary purpose of increasing organisational wealth". Organisational crime may also benefit the individuals involved, for if the organisation benefits, certain individuals or groups within the organisation directly benefit too. This could occur when there is contract fraud, price fixing, money laundering or cost-cutting activities (Miethe, 1999, p. 27). Any increase in profit as a result of these activities may at the same time bring exclusive benefit to certain shareholders within the organisation. As Miethe $(1999$, p. 27) says, “...particular individuals may benefit from the misconduct, but the behaviour is supported by the organisation and is functional for the continued operation of the company". Thus, accusations against the wrongdoer are

${ }^{2}$ Disclosures may be considered unauthorised for a number of additional reasons too. If the disclosure involves the exposure of highly sensitive or classified information (protected by secrecy clauses or confidentiality agreements) to parties that the organisation believes should not have access to this information, the disclosure is considered unauthorised by the organisation (Uys, 2005). In addition, the status of the individual making the disclosure will impact on how the disclosure is viewed. This could occur when "the employee who made the disclosure was not considered senior enough to make the disclosure" (Uys, 2005, p. 7)

${ }^{3}$ Miethe (1999, p. 27) refers to organisational crime as organisational deviance. The definition he provides for organisational deviance is consistent with Miceli and Near's definition of organisational crime. He defines organisational deviance as "criminal acts or violations of widely held moral and ethical standards that are committed to enhance the organisation's position, power, and/or financial resources." 
threatening to the organisation and the wrongdoer's position within the company, and, as such, deterrent measures to reporting and extremely harsh responses are common.

Secondly, there is occupational crime that consists of acts of wrongdoing that are purely self-interested (Miceli \& Near, 1992, p. 171). They are acts that occur "within a work setting that are motivated by individual need and lack organisational support" (Miethe, 1999, p. 27). Miceli and Near (1992, p. 171) state that occupational crimes "are committed primarily to increase individual wealth", but also include "[c]ounterproductive work activities (such as substance abuse on the job, coming to work late or leaving early, taking unauthorised work breaks), prohibited personnel practices (such as discrimination and sexual harassment), financial frauds (such as embezzlement, overcharging for business expenses, falsifying time cards), and poor production or service activities (such as defrauding customers by low-quality service, abuse of clients)"(Miethe, 1999, p. 27). Individuals who reveal cases of occupational crime are usually rewarded for their efforts by the company, but may face hostility from their peers.

Whistleblowing is said to be 'authentic' whistleblowing when the disclosure of information is consistent with the greater good, in the public interest. It is a form of "prosocial behaviour" in that it is concerned with the welfare of a broader interest group - either the public, the organisation or its shareholders. The aim of the whistleblower is to reveal the wrongdoing, and provide information that will allow the complaint recipients to act by ending the wrongdoing (Camerer, 1996; Heacock \& McGee, 1987; Miceli \& Near, 1992), in turn bringing about an increase in organisational effectiveness (Miceli \& Near, 1992) and accountability for actions (Jos, Tompkins \& Hays, 1989). Whistleblowing requires an individual to go beyond the 'call of duty' because of the individual's own sense of ethics rather than any mandated requirement within his/her job specifications ${ }^{5}$.

\section{Reporting and non-reporting as choices}

Employees faced with organisational wrongdoing have a number of choices when deciding whether or not to take action. Firstly, there is the decision of whether or not to report wrongdoing, which is influenced by factors such as the severity and persistence of the problem and typically involves a triggering event (Miceli \& Near, 1992), the characteristics of the organisation (such as its size and structure), a personal sense of ethics, loyalty to the organisation and the belief that redress is possible (Dehn, 2001). Following this, there is the decision of to whom one reports. Usually, this is to an internal authority in the early stages, 'progressing' to other internalauthorities as doors close and retaliation intensifies. Only once internal channels are exhausted, reprisal is fierce and reporting has proved to be unproductive does the whistleblower report externally, often out of desperation.

The decision not to report (termed as 'non-reporting' by Miceli and Near, 1992, p. 4) encompasses two forms, namely remaining silent or discussing the matter with colleagues. Discussing the issue with colleagues is a way of evaluating personal opinions on the matter, determining external knowledge of the wrongdoing and a manner of gauging how the organisation is likely to respond. Both forms of non-reporting are also influenced by a number of factors, ${ }^{6}$ most notably that of organisational culture. Organisational culture may promote a complacency where wrongdoing is normalised, the belief that no corrective action will be taken or the fear of intimidation. Milliken et al. (2003) claim "[e]mployees are often reluctant to share information that could be interpreted as negative or threatening to those above them in an organisational hierarchy", and out of fear, they remain silent. Where the context is considered unfavourable the 'mumeffect' is further intensified. This is when organisational norms and "the quality of one's relationship with senior management" (Milliken et al., 2003, p. 1455) promote perceptions that topmanagement is unwilling to listen, that the organisational culture is unsupportive and that negative consequences (labelling and reprisal) are imminent. Furthermore, it is claimed that unless the individual believes that the wrongdoing will be addressed, "it is almost inevitable that he or she will remain silent" (Dehn, 2001, p. 2)

Interestingly, discussions with colleagues may become transitional points in the process. If, through discussion, an employee finds that there is a culture of silence or that there is little organisational support for voicing concerns about issues, he or she may be encouraged to keep quiet. This is especially true if there is a lack of trust - as is shown in the works of Milliken et al. (2003). However, discussion with colleagues may not always result in employee silence. If the culture of silence is rendered unacceptable to the whistleblower, or if the environment is supportive, whistleblowing will take place nonetheless.

\section{Consequences of reporting and non-reporting}

Internal whistleblowing is emphasised in the literature as the most desirable option for whistleblowers because it offers an earlier opportunity to correct the matter, as it may avoid the more damaging consequences of external whistleblowing (Barnett, 1992; Davis, 1989; King III, 1999; Trevino \& Bart, 1992) or non-reporting. As the PriceWaterhouseCoopers Economic Crime Survey (2005, p. 18) states, "luck is no basis for a strong anti-fraud regime. The earlier the crime is discovered, the lower the risk of damage and the higher the probability of recovering lost assets". Furthermore, according to King III (1999, p. 316) "internal disclosure creates an ethical culture where employees are encouraged to report unethical behaviour." Generally, it is anticipated that if internal whistleblowing takes place within an organisation that fosters a whistleblowing culture, the retaliation suffered by the whistleblower may be mitigated (Dehn, 2001, p. 6).

In contrast, "[e]xternal disclosures bring unwanted public attention to organisations, and since such disclosures concern alleged wrongdoing, they usually put organisations in the worst possible light"(Barnett, 1992, p. 2). Furthermore, by challenging the organisation's authority structure, external whistleblowing may be seen to raise more questions about the capabilities and character of management, and, as a result, whistleblowers are more likely to experience harsher retaliation because of their choice of external reporting (Barnett, 1992, p. 2; Morehead Dworkin \& Baucus, 1998, p. 1286). Other disadvantages of external reporting include litigation and the costs thereof and unfavourable media attention.

Similarly, non-reporting (in both forms) is as destructive as external reporting. Dehn $(2001$, p. 2) says that it will deny "responsible employers ... the opportunity to protect their interests". For if "the wrongdoing is not checked, it may escalate, proving even more costly when it is finally detected ... the wrongdoing may eventually cost the organisation its life" (Miceli and Near, 1992, pp 6-7). Furthermore, Milliken et al. (2003, p. 1454) find that "the silence or information withholding $\ldots$ has the potential to undermine organisational decision making and error-correction and to damage employee trust and morale." Dehn (2001, p. 4) claims that with the culture of silence "unscrupulous competitors, managers or workers are

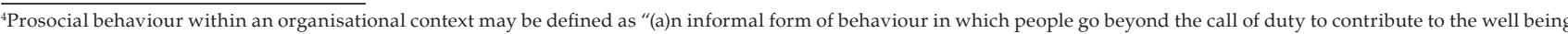
of their organisation and those in it" (Greenberg \& Baron, 2003, p. 408).

In cases where the reporting of organisational wrongdoing is a required function of one's job, going beyond the call of duty would entail moving beyond the mandated reporting requirements within the job specifications, if necessary.
}

${ }^{6}$ Factors include the characteristics of the individual, the message being sent, the relationship with supervisor and the organisational context. 
given reason to believe that 'anything goes'". Remaining silent gives the impression that malpractice is acceptable, and it will therefore continue unchallenged. Dehn (2001) also claims that it has a societal impact, as it denies society the opportunity to address the injustice that whistleblowing delivers to the whistleblower

\section{Impact of retaliation: betrayal of loyalty and trust}

Retaliation in an environment where whistleblowing is considered threatening exists irrespective of the form of reporting. However, what is evident in the section above is that retaliation is instrumental in promoting a culture of intimidation, which in turn lends itself to the possibility of non-reporting - and, in particular, employee silence. At the same time, when internal whistleblowing has occurred, retaliation breaks down processes of trust and leaves external whistleblowing as the only viable option for the whistleblower. As Davis (1989, p. 8) says, "[b]efore the whistleblower was forced to blow the whistle, she trusted the formal organisation. She ${ }^{7}$ took its good sense for granted."

Important to note in this discussion is that prior to internal whistleblowing, when the decision to report is taken, trust exists. However, in the process of reporting, where reprisals are experienced, a lack of trust develops, resulting in nonreporting or external whistleblowing. This suggests that trust in the organisation plays a role in employee's decisions to report wrongdoing and how to report it. The literature, however, does not show any analysis of the relationship between trust and whistleblowing. This is surprising when taking into account the importance of trust in everyday relationships. According to Sztompka (1999), trust is prominent in all basic interpersonal interactions and more so when considerable risks and uncertainty are posed (Sztompka, 1999). If the organisation does not affirm the value of whistleblowing, the potential whistleblower may not trust that $\mathrm{s} /$ he will be met with cooperation, appreciation and collegiality and the chance to protect the organisation.

The next section explores trust and its role within whistleblowing.

\section{Defining trust and organisational trust}

Trust, according to Sztompka (1999, p. 25), is a "gamble" whereby one will choose how to act in uncertain situations. Sztompka (1999, pp. 25-26) defines trust as:

The expectation that other people, or groups or institutions with whom we get into contact - interact, cooperate - will act in ways conducive to our well-being. Because in most cases we cannot be sure of that, as others are free agents, trust is a sort of gamble involving some risk. It is a bet on the future, contingent actions of others.

As an expectation, Sztompka (1999) argues that trust encompasses a belief of how another person, group or institution will behave in the future in response to the action of an individual. The trustor (the person who trusts) makes a commitment to act on this belief, if it is convincing. The commitment to act on this expectation will vary according to the strength of the belief and the type of situation (Sztompka, 1999). This, in turn, involves judgement based on the situation, the characteristics of the trustee (the object in which trust is invested and may be another person, group or institution), and the trustor's willingness to be vulnerable - i.e. to place him/herself at the mercy of an unpredictable response from the trustee. This is the risk that is posed to the trustor. The stronger trust is, the greater the risk taking will be. Furthermore, the greater the expectation that the trustee will act in a benevolent manner - a manner that is conducive to the well-being of the trustor - the greater the position of vulnerability the trustor will be inclined to place him/herself in. It is the chance-taking in decision making that leads Sztompka (1999; 2005) to define trust as a gamble based on an individual's judgement. To simplify the definition, trust in this paper is understood to be the expectancy by the trustor that s/he will be treated with fairness and will not be harmed by the trustee. If trust is the expectancy by the trustor that s/he will be treated with fairness and will not be harmed by the trustee, organisational trust may be defined as the expectancy by the trustor that s/he will be treated with fairness and will not be harmed by the organisation (the trustee).

In accepting this definition, it must be remembered that organisational trust occurs in a specific social context (an organisation or institution), which allows for the development of a unique 'flavour' of organisational trust. This context is related to the culture of the organisation, its specific communication networks and structures, the manner in which relationships and hierarchies are built and maintained and the means by which tasks are achieved. As Claybrook $(2004$, p. 7) states, “... organisations have reputations and images, and they develop routines, processes, and cultures which unify the behaviour of their employees and the responses to external contacts", and therefore will affect the experiences and perceptions of trust at the various levels of interaction (individual, group, institutional) within the organisation.

The factors that promote trustworthiness in an organisation include characteristics such as the organisation's competence, integrity, reliability, openness and honesty, concern for employees and identification (Claybrook, 2004, p. 4; Delahaye Paine, 2003, p. 5; Gillis, 2003, p. 11; Shockley-Zalabak, Ellis \& Cesaria, 2003, p. 7).

Competence refers to an organisation's effectiveness in competing and surviving in the marketplace (Delahaye Paine, 2003, p. 5; Gillis, 2003, p. 11). According to Gillis (2003, p. 11), effectiveness may be perceived from "intelligence; clarity of thinking; communication skills and problem solving, crisis management and decision-making". In the case of whistleblowing, it may relate to the complaint recipient's effectiveness in dealing with the wrongdoing.

Integrity involves the belief that the organisation is just and fair (Shockley-Zalabak et al., 2003, p.7). In this sense, it involves perceptions around the treatment of employee, and the manner in which procedures and processes deliver equitable practices and solutions for employees. This is particularly relevant to whistleblowing.

Reliability is whether an organisation's actions are consistent and dependable (Delahaye Paine, 2003, p. 5; Gillis, 2003, p. 11; Shockley-Zalabak et al., 2003, p. 7). It is the "belief that an organisation will do what it says it will do" (Delahaye Paine, 2003 , p. 5) and therefore can be relied upon for support or assistance. In whistleblowing, this is based on the belief that the organisation will appreciate the report and will respond transparently and effectively to the matter.

Openness and honesty refers to the amount, accuracy, and sincerity of information shared (Delahaye Paine, 2003, p. 5; Gillis, 2003, p. 11; Shockley-Zalabak et al., 2003, p. 7). This may be absent if whistleblowing is perceived as threatening to the organisation and its leaders or managers.

Concern for employees includes "feelings of caring, empathy, tolerance and safety that are exhibited when we [employees] are vulnerable in business activities" (Delahaye Paine, 2003, p. 5). This would involve not harming the whistleblower or 


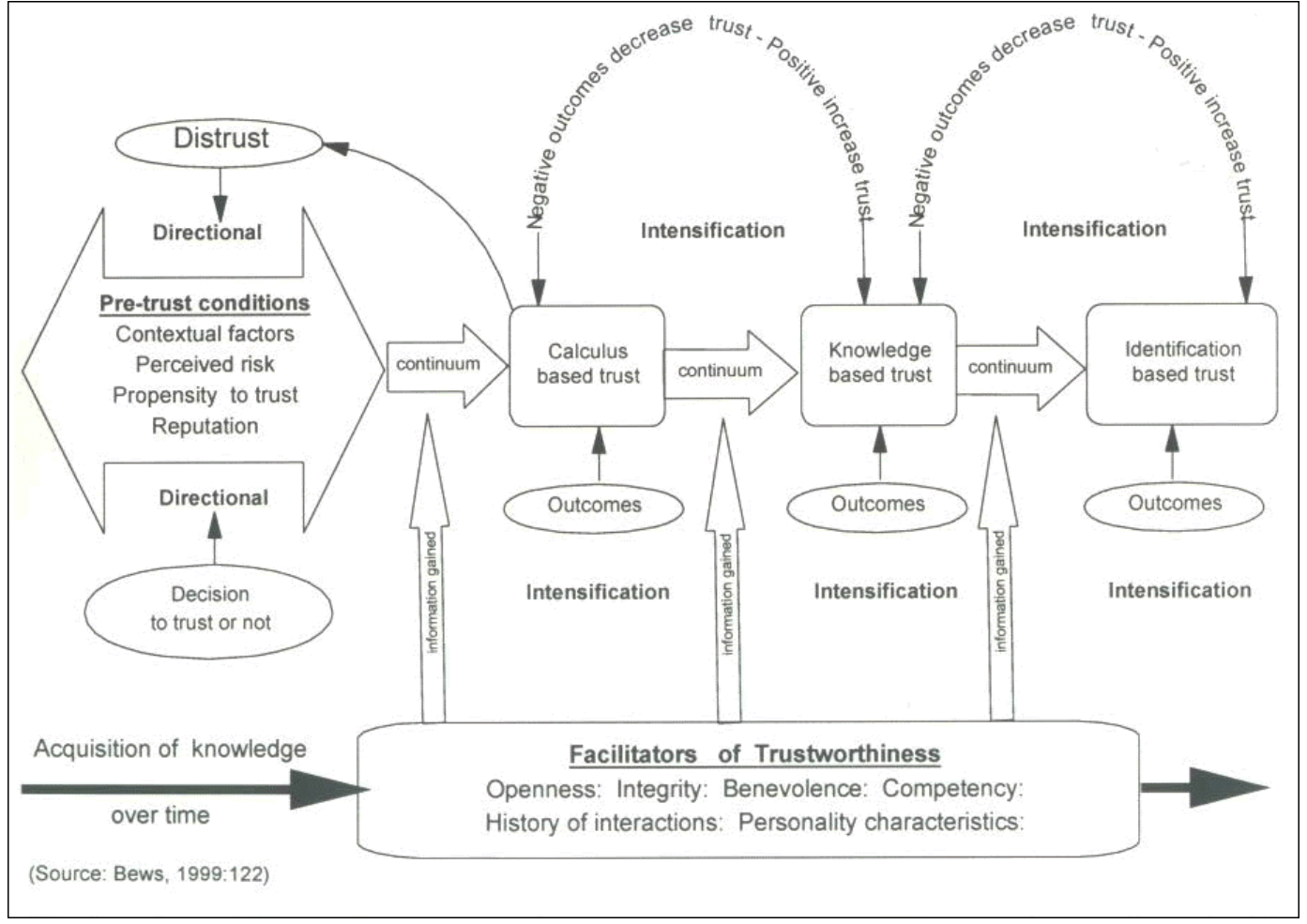

FIGURE 1

Development of organisational trust (Source: Bews, 1999, p. 41)

protecting the whistleblower from any occupational harm.

Finally, Delahaye Paine (2003, p. 5) states that identification refers to the extent to which managers and co-workers feel connected to the organisational culture, in other words, "the extent to which we hold common goals, norms, values and beliefs with our organisation's culture". Thus views regarding the correction of organisational wrongdoing must be compatible between the whistleblower and the organisation.

\section{Development of organisational trust}

Trust is a dynamic, multidimensional and interactional phenomenon that develops over time through a series of stages. In order to understand the development of trust, it must firstly be noted that three forms of trust are typically identified. As expounded by Lewicki and Bunker (1996), these are calculusbased trust, identification-based trust and knowledge-based trust.

Calculus-based trust is based on a calculation of the benefits or rewards for preserving trust, or the avoidance of punishment or detriment of violating trust (Lewicki \& Bunker, 1996). Lewicki and Bunker (1996, p. 120) state, "[i]n this view, trust is an ongoing, market-oriented, economic calculation whose value is derived by determining the outcomes resulting from creating and sustaining the relationship relative to the costs of maintaining or severing it". Their opinion is that the deterrenceseeking elements are stronger motivators than the benefitseeking elements of the relationship. Trust at this stage is at its most sensitive, as it occurs at an early stage of the relationship with no previous knowledge of probable behaviour should the relationship become threatening. Due to this fact, one would be less willing to pursue the risks of engagement. Calculus-based trust is the first stage of trust, and is quite partial and fragile (Lewicki \& Bunker, 1996).

Knowledge-based trust is grounded in an established relationship that has grown out of calculus-based trust, and as a result, a significant amount of knowledge is available to both parties regarding the relationship and the trustworthiness of each party. The knowledge gained from the relationship contributes to the predictability of behaviour, and decisions to continue with the relationship are based on information rather than calculated decisions of deterrence (Lewicki \& Bunker, 1996). Furthermore, the predictability of behaviour contributes to the enhancement of trust. Knowledge-based trust requires ongoing communication for relationship building and an understanding of the multi-dimensional elements of trust - which in turn indicates when trust is likely to be violated or enhanced (Lewicki \& Bunker, 1996). As such, knowledge-based trust is fundamentally different from calculus-based trust, although it develops from calculus-based trust.

Identification-based trust is based on identification with the other's desires and intentions (Lewicki \& Bunker, 1996). Both parties appreciate each other's wants and this results in a mutual understanding between the parties. Trust at this level is strong enough to allow one party to represent another party in its absence (Lewicki \& Bunker, 1996). Trust at this stage also brings an understanding of what is required to sustain the other's trust. As Lewicki and Bunker $(1996$, p. 123) state, "increased identification enables one to 'think like' the other, 'feel like' the other, and 'respond like' the other'"'. In organisations, this often results in co-operative behaviour as opposed to self-interested behaviour (Lewicki \& Bunker, 1996). The issue of identity is important within identification-based trust. This group identity may be incorporated into the individual's own identity, and as this strengthens, so does co-operative behaviour, resulting in a strengthening of trust through an enhanced identification of the needs being met in the relationship.

Using the various forms of trust mentioned above, the development of organisational trust may be explained referring to figure 1, as presented by Bews (1999, p. 41):

1. The development of trust can be seen as sequential and moves from calculus-based trust, to knowledgebased trust and then to identification-based trust. The development process is one that evolves and changes. However, not all relationships of trust reach maturation for various reasons, depending on the relationships and 
the forces impacting on it.

2. There is significant overlap between the stages of development. Each stage precipitates the next through action typical of its nature. Calculus-based trust is the first stage of trust, and is relatively partial and fragile (Lewicki \& Bunker, 1996). This knowledge lays the foundation for knowledge-based trust. In knowledgebased trust, individuals continuously strive to learn about the other. As learning increases, so identification with the other party increases. When this identification becomes the basis of the relationship, the transition to identification-based trust has been made.

3. The change from one stage to the next is characterised by a paradigm shift. For example, the change from knowledge-based trust to identification-based trust is located in a shift "from extending one's knowledge about the other to a more personal identification with the other" (Lewicki \& Bunker, 1996, p. 125)

4. The development of trust may be facilitated by interaction between individuals and factors of trustworthiness. Bews (1999, p. 26) includes openness, integrity, benevolence, competency, personality factors and history of interactions as factors of trustworthiness. In this study, the factors of trustworthiness are limited to competence, integrity, reliability, openness and honesty, concern for employees and identification between the parties.

5. The decision to trust is also influenced by the contextual climate of the environment - it will influence the identification of risk and the trustor will often consider the reputation of the trustee.

6. Trust is not a linear process. If the relationship suffers damage, trust is likely to decline. Trust may evolve through a process, but it may also devolve.

Understanding how trust develops helps one understand how relationships in an organisation develop and how they break down. However, in the literature, very little mention is made of trust in whistleblowing contexts or how organisational trust, and its development or breakdown, may affect, or is affected by, whistleblowing. Instances where trust was mentioned in the literature are noted and discussed below.

\section{The role of trust in whistleblowing}

Understanding the development of trust allows us to understand the likely impact trust has on reporting choices. The literature says very little about the relationship between the two. Where trust is directly discussed, it refers to 1) how trust is damaged through the process of retaliation (as is evident in the foregoing sections) and then 2) the likely impact it has on internal whistleblowing. The relationship between supervisor and subordinate (King III, 1999; Uys, 2000b) appears to be of particular relevance here. If a strong relationship of trust is found, reporting to the supervisor will take place (internal reporting). Uys (2000b) emphasises that the relationship between supervisor and subordinate will promote internal whistleblowing if the supervisor's word can be trusted. This relates to an "assurance that they will not be victimised if they use these channels to report unethical behaviour" (Uys, 2000b, p. 266). King III (1999) views the supervisor-subordinate relationship as a structural issue that will remove impediments to upward reporting, provided that the supervisor acts on the issue. In this regard, King III argues that organisational structure is very important in allowing for internal whistleblowing to take place, starting with the supervisor-subordinate relationship. Uys (2000b) agrees, stating that the organisation should be restructured to facilitate the reception of bad news. She states that "communication channels of the organisation should be opened up so that nobody is in a position to prevent bad news from filtering through to the highest structures" (Uys, 2000b, p. 266).

What needs to be examined, then, is how trust may affect a whistleblower's decisions. If trust exists, will potential whistleblowers take the risk and blow the whistle? If so, would they blow the whistle internally, since they expect fair treatment or even rewards for the actions? On the other hand, if there is a lack of trust, will the risk of reporting be too great, resulting in employee silence? Alternatively, if there is a lack of trust, will that drive the whistleblower to external reporting instead, if it is perceived that the external means are the only means of receiving fair treatment and no harm as a result of the whistleblowing?

Therefore, the hypotheses explored were:

H1: The higher the level of organisational trust, the higher the chances of internal whistleblowing.

H2: The higher the level of organisational trust, the lower the chances of only keeping quiet.

H3: The higher the level of organisational trust, the lower the chances of external whistleblowing.

\section{RESEARCH DESIGN}

A South African company operating within the Information and Communication Technology (ICT) sector was selected as the site for this research. The high levels of fraud prevalent within the company ${ }^{8}$ made it a particularly relevant and interesting context for this research project. It also raised questions around what kind of a trust environment the company was likely to embody.

\section{Research approach}

A quantitative design of this nature was employed for a number of reasons: Given the prevalence of fraud at the time of research, it was felt that employees may have been sensitive to the issue. It was conceivable that some employees could have been aware of cases of organisational wrongdoing or could have reported cases of organisational wrongdoing. In addition, some employees may have considered reporting, or were in the process of reporting, cases of wrongdoing. Another factor of concern was how the research itself would be perceived. Informal discussions with management revealed that employees may consider this survey as a 'plot' to uncover further information of wrongdoing and to identify the individuals involved. As a result of these concerns, a reluctance to participate in the survey for fear of identification and other consequences arose amongst employees - which is in itself a powerful indication of the extent to which whistleblowing is perceived as hostile to the organisation. It was recognised that the sharing of information of this kind may be extremely threatening to their well-being within the company and in general. Therefore, given the sensitive nature of the topic, every effort was made to ensure anonymity and confidentiality, and it was felt this could be best achieved through the use of a survey that would be conducted amongst all employees. By doing so, there would be less of a threat to the respondent in terms of identification.

\section{Participants / respondents}

In order to test the relationship between organisational trust and whistleblowing in the selected organisation, a survey comprising of self-completion questionnaires was conducted. Because of the sensitivity to the research topic, the questionnaires were distributed, with permission from the Human Resources Division, to every member within the organisation, and all employees were encouraged to participate. The questionnaires were deposited and collected from a central point within each 
TABLE 1

Results of diagnostic tests

\begin{tabular}{llll}
\hline CONSTRUCT & KMO & BARTLETT'S & MSA \\
\hline Organisational trust & 0.942 & 0.000 & 0.942 \\
Keep quiet & 0.804 & 0.000 & 0.600 \\
Report to an authority within the company & 0.906 & 0.000 & 0.600 \\
Report to an authority outside of the company & 0.868 & 0.000 & 0.600 \\
\hline
\end{tabular}

department during the period of the survey.

A $16 \%$ response rate was achieved, with 129 usable selfcompletion questionnaires out of 676 . Even though this was a self-selected sample, based on the similarities between the demographic variables of the sample and the population overall, it was concluded that the sample was representative of the population. The average age of the sample and the population were very close, with 34.38 years (range at 24-61 years) and 35 years (20-56 years) respectively. The number of completed years of employment for the sample at 6.7 years (1-18 years) and the population at 6.4 years ( $0-20$ years) were also very similar. The staff level and basis of employment of the sample also closely resembled the population. Furthermore, the respondents had been in the employ of the company for 6.15 years on average, indicating established relationships with the company. Only $9.7 \%$ of the sample had been in the employ of the company for 2 years or less (range 1-18 years). The only notable difference found in the sample was that of the gender, where the sample consisted of fewer females than the population. The sample contained $48.1 \%$ females whereas the population contained $52.8 \%$ females. In order to clarify whether or not the sample's gender profile would render the sample different to the population, a hypothesis test was conducted. As the pvalue from the Chi-Square test was 0.058, the null hypothesis that the sample is independent of gender could not be rejected. Similarly, the Phi value was -0.076 , showing no effect on the sample.

\section{Measuring instruments}

The self-completion questionnaire comprised four sections. These were:

Section A: Demographics: Included were age, gender, length of employment, type of employment, staff level and department;

Section B: Trust in the organisation (referred to as "organisational trust"): Twenty items were adapted from an existing questionnaire, based on a study of the factors of trustworthiness at a South African financial institution (Bews, 1999). The selected questions were carefully chosen to equally represent the five factors constituting trustworthiness in an organisation, namely openness/integrity, honesty, concern, competence, reliability and identification (Claybrook, 2004; Delahaye Paine, 2003; Gillis, 2003; Shockley-Zalabak et al., 2003). Questions were asked regarding the openness and honesty of the organisation's leaders towards its employees, concern for employees' wellbeing, competence of the organisation to deal with matters and to deal with these matters reliably and whether identification with the goals of the organisation are mutually realised by employees and employers.
The 20-item instrument used a 5-point Likert-type scale (coded such that $1=$ to no extent and $5=$ to a very large extent).

Section C: Whistleblowing: Consisted of 10 items which were conceptualised from actual cases of wrongdoing witnessed within the company. These were generated from examples discussed in an interview with the general manager of the Human Resource Department and included examples of organisational crime ${ }^{9}$ and occupational crime $^{10}$. Each item was presented as a vignette to which respondents could indicate whether, and to what extent, they would respond internally, externally or not at all. This 10-item instrument also used a 5 -point Likert-type scale for each whistleblowing option (coded such that $1=$ to no extent and $5=$ to a very large extent).

Section D: Knowledge and behaviour regarding reporting at the company: Questions around behaviour and knowledge of whistleblowing within the company were posed. In particular, this short section investigated whether any reporting had taken place and, if not, what the possible reasons may be. Reasons for not reporting included that the respondent felt that s/he would not be believed, that s/he would be dismissed, that the matter would not be attended to, that $\mathrm{s} /$ he was disinterested in such matters, that $\mathrm{s} /$ he feared punishment due to previous experience of reporting, and that it was too much trouble and that the company would not protect him/her against any repercussions.

\section{Statistical analysis}

Scales were constructed for organisational trust, employee silence (referred to as 'keep quiet') and internal and external whistleblowing. Prior to the testing of these scales, diagnostic tests were conducted to determine the suitability of the constructs. The diagnostic procedures aimed to determine construct validity of 'organisational trust', 'keep quiet', 'report to an internal authority' and 'report to an external authority' via the use of sampling adequacy ${ }^{11}$. Table 1 above indicates the results of these tests.

Pursuant to the tests above, each of the constructs were developed into scales using factor analyses.

Starting with organisational trust, the extraction and rotation methods ${ }^{12}$ initially produced three factors. The eigenvalues for these three factors were 11.83 for factor one, 1.14 for factor two and 1.02 for factor three. A second-order factor analysis was done, and two factors were generated, with items 1-4 and 6-20 loading onto one factor. Factor one developed in the secondorder analysis was called organisational trust and was accepted as the construct to test the relationship between organisational trust and internal whistleblowing, external whistleblowing and keeping quiet. Factor two loaded only one item (item 5 - leaders taking advantage of the vulnerability of employees), and since it consisted of only one item, it could not be accepted as an instance of organisational trust.

With 'keep quiet', the first-order factor analysis extracted three factors with an eigenvalue greater than 1.0. This was rotated,

\footnotetext{
"For example: cash fraud, stock-control fraud, internet billing system abuse, expropriation of funds, radiation from a satellite dish posing risk to public health and safety of surrounding community, and job promotion through sexual favouritism.

${ }^{10} \mathrm{For}$ example: usage of illegal substances (such as drugs) at work, dishonest use of company assets for personal gain and petty theft.

${ }^{11}$ Sampling adequacy establishes whether there are significant correlations, and therefore linear relationships, between the items separately constituting each construct. The basic assumption is that if items are measuring the same 'thing', they will significantly correlate with each other. This, in turn, indicates that the construct has validity as a statistical item, and then a factor analysis may be conducted. Sampling adequacy was established by using three tests: 1) the Kaiser-Meyer-Olkin Measure of Sampling Adequacy (KMO), which must be greater than 0.7; 2) Bartlett's Test of Sphericity, with a p-value that must be less than 0.05 and 3) the Measure of Sampling Adequacy Per Item (MSA), which must be greater than 0.6 . If all the values comply, the sampling adequacy for each item can be accepted. In other words, the sample adequacy of each construct is adequate to do a factor analysis. ${ }^{12}$ This applied to each construct, where relevant. As each of the constructs were measured on ordinal scales, the extraction method of the first-order factor analyses was Principal Axis Factoring, and the rotated method for the second -order factor analyses was conducted using Varimax with Kaiser Normalisation

${ }^{13}$ Refer to note 12 for the name of the first- and second-order factor analyses conducted on each of the constructs described here.
} 
TABLE 2

Results of factor analysis - organisational trust

\begin{tabular}{|c|c|c|c|c|}
\hline ORGANISATIONAL TRUST & $\begin{array}{l}\text { NO. OF } \\
\text { FACTORS }\end{array}$ & FACTOR 1: ITEMS LOADED & FACTOR 2: ITEMS LOADED & FACTOR 3: ITEMS LOADED \\
\hline $\begin{array}{l}\text { First order } \\
\text { (Principal Axis Factoring) }\end{array}$ & 3 & $\begin{array}{l}11 \text { - loyalty to its employees } \\
8 \text { - honour commitment to employees } \\
19 \text { - leaders are supportive of employees } \\
10 \text { - leaders act in best interest in situation } \\
\text { of risk } \\
15 \text { - prepared to place future in hands of } \\
\text { company's leaders } \\
13 \text { - leaders show flexibility in terns of } \\
\text { rules and regulations } \\
14 \text { - leaders are knowledgeable about } \\
\text { their jobs } \\
7 \text { - procedures and rules are in place that } \\
\text { focus on treating people fairly } \\
12 \text { - rules and regulations are consistently } \\
\text { implemented }\end{array}$ & $\begin{array}{l}3 \text { - leaders act in a decisive manner } \\
2 \text { - leaders behave in a trustworthy manner } \\
1 \text { - leaders retain control of issues } \\
\text { important to employees } \\
20 \text { - leaders can be trusted } \\
6 \text { - management is focused on doing the } \\
\text { right things rather than complying with } \\
\text { statutes } \\
17 \text { - the company's intentions can be } \\
\text { trusted } \\
18 \text { - procedures are in place to ensure fair } \\
\text { treatment of employees } \\
16 \text { - employees are treated equally } \\
19 \text { - fair processes are valued more than } \\
\text { outcomes } \\
4 \text { - the company is well-managed }\end{array}$ & $\begin{array}{l}5 \text { - leaders take advantage of the } \\
\text { vulnerability of employees at } \\
\text { the company }\end{array}$ \\
\hline $\begin{array}{l}\text { Second order } \\
\text { (Varimax with Kaiser } \\
\text { Normalisation) }\end{array}$ & 2 & $\begin{array}{l}\text { Items } 20,17,19,10,15,8,16,4,9,11,2 \text {, } \\
18,7,14,3,1,6,12,13 \text {. } \\
\text { (see item descriptions above) }\end{array}$ & $\begin{array}{l}\text { Item } 5 \\
\text { (see item descriptions above) }\end{array}$ & - \\
\hline
\end{tabular}

TABLE 3

Results of second order factor analysis - three whistleblowing constructs

\begin{tabular}{|c|c|c|c|}
\hline WHISTLEBLOWING CONSTRUCT & NO OF FACTORS & FACTOR 1: ITEMS LOADED & FACTOR 2: ITEMS LOADED \\
\hline $\begin{array}{l}\text { Keep quiet } \\
\text { (Varimax with Kaiser Normalisation) }\end{array}$ & 1 & $\begin{array}{l}1 \text { - non-disclosure of conflict of business interests } \\
2 \text { - smart card fraud } \\
3 \text { - billing system abuse and theft } \\
4 \text { - accounting fraud and threat to safety } \\
5 \text { - stock theft } \\
6 \text { - drug use at work } \\
7 \text { - deliberate misrepresentation of sales figures } \\
8 \text { - sexual favouritism } \\
9 \text { - dishonesty / fraud } \\
10 \text { - dishonesty regarding radiation }\end{array}$ & - \\
\hline $\begin{array}{l}\text { Report to an authority within the company } \\
\text { (Varimax with Kaiser Normalisation) }\end{array}$ & 2 & $\begin{array}{l}1 \text { - non-disclosure of conflict of business interests } \\
2 \text { - smart card fraud } \\
3 \text { - billing system abuse and theft } \\
4 \text { - accounting fraud and threat to safety } \\
5 \text { - stock theft } \\
7 \text { - deliberate misrepresentation of sales figures }\end{array}$ & $\begin{array}{l}6 \text { - drug use at work } \\
8 \text { - sexual favouritism } \\
9 \text { - dishonesty / fraud } \\
10 \text { - dishonesty regarding radiation }\end{array}$ \\
\hline $\begin{array}{l}\text { Report to an authority outside of the company } \\
\text { (Varimax with Kaiser Normalisation) }\end{array}$ & 2 & $\begin{array}{l}9 \text { - dishonesty / fraud } \\
7 \text { - deliberate misrepresentation of sales figures } \\
3 \text { - billing system abuse and theft } \\
8 \text { - sexual favouritism } \\
6 \text { - drug use at work } \\
1 \text { - non-disclosure of conflict of business interests } \\
5 \text { - stock theft }\end{array}$ & $\begin{array}{l}4 \text { - accounting fraud and threat to safety } \\
2 \text { - smart card fraud } \\
10 \text { - dishonesty regarding radiation }\end{array}$ \\
\hline
\end{tabular}

and one factor was then extracted in the second-order factor analysis ${ }^{13}$. The eigenvalue for the second-order factor analysis was 1.98. The factor analysis confirmed that the items of the construct measured employee silence, and therefore this construct is referred to as 'keep quiet' (see table 3). The firstorder factor analysis on reporting to an authority within the company extracted two factors. The eigenvalues for the two factors were 5.64 and 1.12 respectively. These two factors were included in the construct and were referred to as 'report to an authority within the company' (as shown in table 3). With regards to reporting to an authority external to the company, the first order factor analysis extracted two factors. The eigenvalues for the two factors were 5.609 and 1.002 respectively. These two factors were accepted as 'report to an authority external to the company' (as shown in table 3).

Based on the outcome of the factor analysis, the scale for organisational trust and the scales for the whistleblowing constructs were adjusted to a scale of 1-100 in order to allow for a more "convenient" comparison of the constructs using equal scales, as item 5 did not load onto organisational trust. The scale had to change in order to allow for the 19 items making organisational trust to be compared equally with the three whistleblowing constructs. Table 4 shows the adjusted scale statistics for organisational trust and the three whistleblowing options reported on in this article.

Table 4 shows that 'report to an authority within the company' has the highest average score across the factor, with a score of 70.29 indicating a high rate of agreement with this whistleblowing option. This is followed by 'organisational trust' and 'discuss with colleagues', with middle-range scores of 55.25 and 46.85 respectively. 'Report to an authority outside of the company' and 'keep quiet' have the lowest scores, showing that most employees do not agree with pursuing these options. Low-range scores were classified as those scores between 0 and $33 \%$, middle-range scores as $34 \%-66 \%$ and high-range scores as $67 \%-100 \%$. Table 5 indicates the scores for Cronbach's Alpha and the Item Analyses which show internal reliability of the constructs for organisational trust and whistleblowing.

\section{RESULTS}

The testing of the relationship between organisational trust and whistleblowing was conducted using Pearson's Product Moment Correlation Coefficient. The results showed that a significant and negative relationship between 'organisational trust' and 'keep quiet' existed ( $p=0.006$ and $r=-0.281)$ indicating that as organisational trust increases, the likelihood of keeping quiet decreases. Similarly, the relationship between organisational trust and internal whistleblowing was significant and positive $(\mathrm{p}=0.001$ and $\mathrm{r}=0.328)$ meaning that as organisational trust increases, so does the likelihood of internal whistleblowing. Finally, the relationship between organisational trust and external whistleblowing was not established. The null 
TABLE 4

Scale statistics for the adjusted constructs

\begin{tabular}{llll}
\hline CONSTRUCTS & MEAN & $\begin{array}{l}\text { STANDARD } \\
\text { DEVIATION }\end{array}$ & $\begin{array}{l}\text { N } \\
\text { (VALID) }\end{array}$ \\
\hline Organisational trust & 55.25 & 21.35 & 109 \\
Keep quiet & 22.48 & 20.66 & 106 \\
$\begin{array}{l}\text { Report to an authority within the company } \\
\begin{array}{l}\text { Report to an authority outside of the } \\
\text { company }\end{array}\end{array}$ & 70.29 & 24.76 & 103 \\
\hline
\end{tabular}

TABLE 5

Reliability - results of Cronbach's Alpha and Item Analysis

\begin{tabular}{lll}
\hline CONSTRUCT & $\begin{array}{l}\text { CRONBACH'S } \\
\text { ALPHA }\end{array}$ & $\begin{array}{l}\text { ITEM } \\
\text { ANALYSIS }\end{array}$ \\
\hline Organisational trust & 0.96 & 19 items \\
Keep quiet & 0.85 & 10 items \\
Report to an authority within the company & 0.91 & 10 items \\
Report to an authority outside of the company & 0.92 & 10 items \\
\hline
\end{tabular}

hypothesis stating that there is no relationship between organisational trust and external whistleblowing was accepted $(p=0.720)$. In other words, this sample showed that employees are more likely to report internally when they place trust in the organisation and more likely to keep quiet when no organisational trust exists. This study was able to show that a significant relationship existed between organisational trust and internal whistleblowing and organisational trust and employee silence, within this particular sample.

In support of this finding, it is worth looking at the reasons respondents provided for not reporting ${ }^{14}$. These responses are consistent with indicators of low-trust relationships, as they illustrate the belief that the company would not protect employees from harm, that the company itself would punish employees for disclosures or that no action would result ${ }^{15}$. One respondent stated, "What is the use because the same people one has to report these incidents to are the people doing those [sic] wrong?" Another respondent indicated that the effort of reporting would be futile, as it is a "time wasting effort - they [management] look after each other". Similar sentiments were echoed by others:

If you do not have a video tape you will be sued alone. HR [human resources] will tell the culprit who reported them.

Upper level covers the lower level in terms of wrongdoing.

Management have pals in higher management - they know they can't be touched.

Management are [sic] buddies with their seniors $\mathcal{E}$ nothing will be done. Employees have interests in other business which conflict with their jobs and are using [the company] to fund this... managers get TVs, sound systems and money through [the company] but nothing is done about it.

Also, interestingly, in a separate response to the above, another respondent raised the issue of race, claiming that "if you belong to a certain race group - you feel you are protected". The perception that members of a certain race group constituting the 'in-group' would be immune from investigation appeared as a reason why, again, reporting would be futile.

A lack of trust in management is evident in these answers.
TABLE 6

Organisational trust, internal whistleblowing and keep quie

\begin{tabular}{lllll}
\hline & & \multicolumn{3}{c}{ ORGANISATIONAL TRUST } \\
\cline { 3 - 5 } & & Low & Medium & High \\
\hline Internal whistleblowing & Low & $\mathrm{X}$ & & $?$ \\
& High & & $\mathrm{X}$ & $?$ \\
\hline Keep quiet & Low & & $\mathrm{X}$ & $?$ \\
& High & $\mathrm{X}$ & & $?$ \\
\hline
\end{tabular}

Management is perceived to be the wrongdoers and the protectors of their own interests - not the organisation or its employees. Disclosure is considered to be pointless. Two detailed cases of wrongdoing emerged in the responses as illustrations of the fact that management had failed to respond in the past:

The fraud perpetrated by [person $x]^{16}$, started as a scam being run by one of our leading equipment suppliers, in conjunction with [person $x$ ], who also distributed smart cards. One of our middle managers [person y] was aware of this (party to it?) and in fact this person authorised the distribution of ... smart cards to this supplier. In the meantime [person x] formed his own syndicate, cut the equipment supplier and the manager out of the loop and carried on by himself ... This fraud went on for 4 years. At different times some of our agents were offered cheaper rates of subscription by our internal staff as well as by the equipment supplier. At various stages during this period a number of staff voiced their concerns, but nothing ever came of it. In fact one staff member almost exposed [person $x$ ] and his syndicate, but [person $x$ ] managed to convince [the managing director] to fire him before he could do anything about it. In the meantime, this manager [person y] has manipulated field tests that have resulted in the same equipment supplier being listed as our preferred supplier for the Africa division.

There has been fraud in the South African "sales and marketing division" on a scale that is far bigger than [the above example]. This involves an "office affair" that led to this lady being promoted from sales rep to senior management, manipulating ... subsidies, and ... prices $\mathcal{E}$ distribution on a grand scale for another leading equipment supplier. This particular person is now the proud owner of a huge farm worth millions of rands that she supposedly bought, from this equipment supplier, with the knowledge of top management, for an absolute song. Even today these arrangements are still in place and she is seen as a very powerful figure in our organisation [sic].

Finally, although the data indicates a relationship between organisational trust, keeping quiet and whistleblowing in converse ways, it must be noted that the scale statistics indicated that organisational trust within this sample was considered to be of a medium level (refer to Table 5). Therefore, results of the relationship are applicable to low and medium levels of trust for keeping quiet and internal whistleblowing respectively. This will be returned to in the discussion of the results.

\section{DISCUSSION}

The relationship between organisational trust and internal whistleblowing is summarised in Table 6 above. The table excludes external whistleblowing because a relationship between organisational trust and external whistleblowing could not be established.

Table 6 illustrates that if a low level of organisational trust exists, an individual is more likely to keep quiet and less likely to blow

\footnotetext{
${ }^{4}$ The final question of the questionnaire asked whether any respondents had information of wrongdoing and had not reported it. Reasons for not reporting were requested, and respondents could select from fixed options provided. However, there was also an open-ended option "other" from which the above responses are derived.

${ }^{15}$ Other reasons included that the employees felt it to be too risky, thought that they would not be believed, were fearful of reprisal from colleagues, thought that it would not be worth the trouble and/or felt that they would be dismissed and punished.
}

${ }^{16}$ Names of persons and products that may lead to the identification of the company, or persons, have been omitted from the quotations in order to protect confidentiality. 


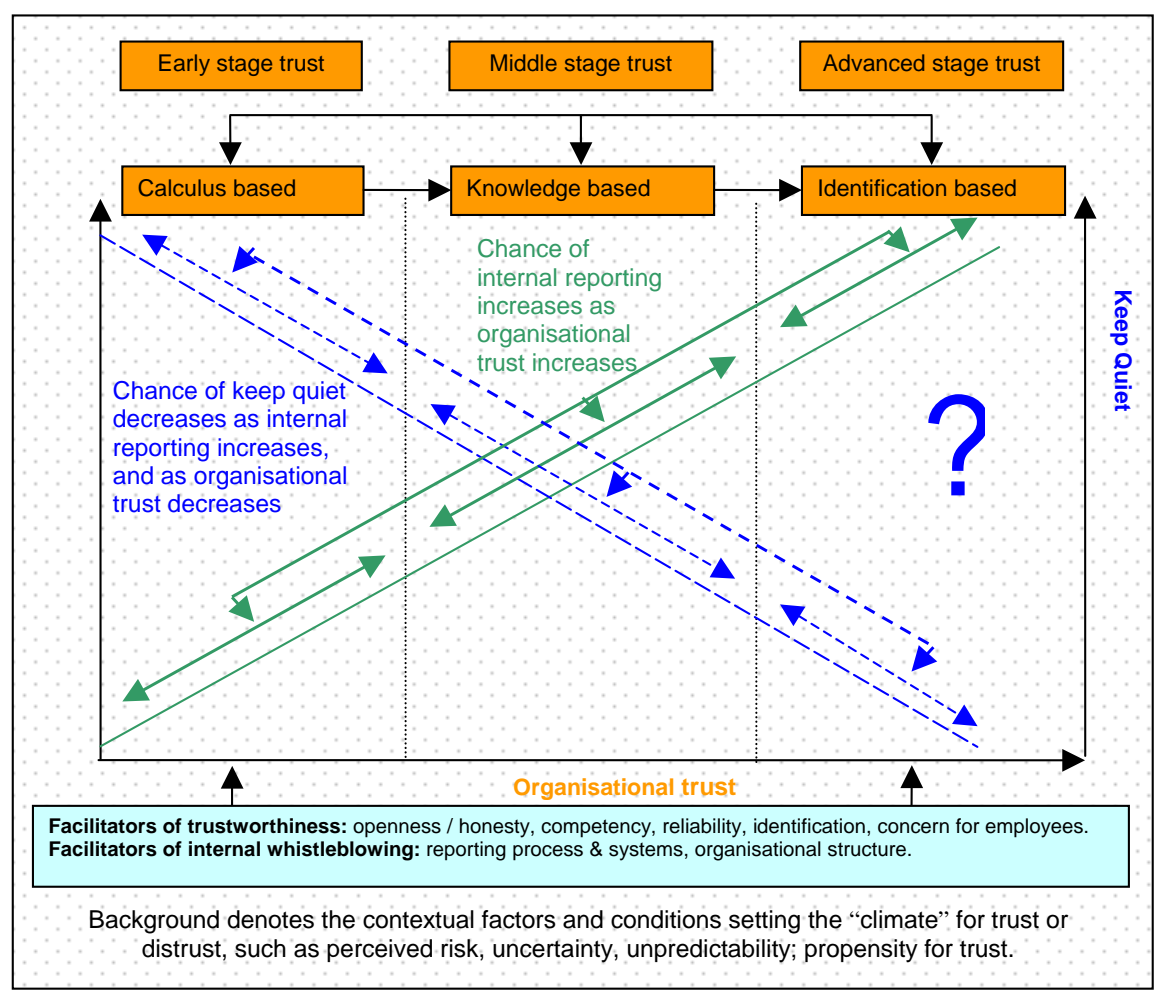

FIGURE 2

The relationship between organisational trust, internal whistleblowing and keeping quiet

the whistle internally. Although this points to the existence of a culture of fear or silence, it also raises the question of whether the employee believes that the organisation will deal with the matter on its own without the need for whistleblowing. Furthermore, racial issues emerged as a feature of distrust and a reason for employee silence. Although this study was not set up to explore this issue, it highlights an important tension with significant implications for South African organisations, and therefore should be further investigated.

Although the hypothesis tests showed a positive correlation between organisational trust and internal whistleblowing, this result must be treated with caution. It cannot unequivocally be said that the higher the level of organisational trust, the higher the level of internal whistleblowing - especially as the data did not provide conclusive evidence for this with high levels of trust. This finding can be applied up to a medium level of trust, as defined according to the scale statistics for this sample. This could be inferred from the fact that a very high level of trust may result in such a strong base of identification that the issue may become an even greater conflict of loyalties, which in turn could discourage any form of whistleblowing.

Thus, the effect of organisational trust on whistleblowing may be contradictory. On the one hand, a low level of organisational trust may be responsible for non-reporting. On the other hand, a very high level of trust may have the same effect, as it could lead to disbelief that the organisation can behave in such an abominable way. Potential whistleblowers may close their eyes to such wrongdoing, based on the belief that their organisation would not allow such harm to take place. Alternatively, as identification with the norms and values of the organisation become assimilated, the individual may lose perspective as $\mathrm{s} /$ he internalises the acceptability of a culture of silence. The implications are that an excessive amount of trust may result in non-reporting. Thus, a critical question is raised: Does this mean that high levels of organisational trust undermine ethical responses to organisational wrongdoing in the same way that low organisational trust does? Based on this thought, it is important for future studies to explore to what degree trust may be necessary to promote internal whistleblowing and avoid a situation of employee silence. 'Keep quiet' / employee silence emerged as a very interesting finding.

The absence of external whistleblowing, although excluded from the table, should not be dismissed as unimportant. For, although there appears to be no relationship between organisational trust and external whistleblowing, this may be attributable to other factors. For example, in this sample, would external whistleblowing be resorted to as a means of political behaviour or for personal gain, where trust has no relevance? Alternatively, perhaps a lack of reporting systems, a lack of knowledge of policies and the fear of retaliation are contributing factors too. It may also simply mean that external whistleblowing, irrespective of whether organisational trust exists or not, is possible.

If one merges the findings of Table 6 with Bews' (1999) depiction of the development of organisational trust (see Fig. 1), one is able to understand more broadly how organisational trust, internal whistleblowing and employee silence are related. 'Keep quiet' and internal whistleblowing are conversely correlated, with a low and high level of organisational trust respectively. This may be interpreted as follows:

In a situation where organisational wrongdoing has been reported or where a case of reporting is being considered, a number of consequences may be expected. Firstly, the literature finds that the organisation may be unresponsive, in the hope that the matter will be dropped if ignored. Secondly, and alternatively, organisations may be overly responsive, but in a hostile manner. Both may be perceived as a lack of competence and/or dishonesty and lack of integrity. Therefore, the expectation of fair treatment and being "free of harm" cannot be claimed by the whistleblower with any certainty. The whistleblower is most likely to reconsider his/her actions, and reporting alternatives will be raised. In this case, the results show, contrary to the literature, that external reporting is most likely not to occur, but employee silence may be expected, and a 
destructive escalation of conflict is likely to continue. Trust will probably be eroded and will continue to erode as organisational retaliation increases in severity - creating a downward spiral of trust from any one of the stages that may have existed (identification-, knowledge- and calculus-based trust). However, the existence of trust in a best case scenario, where no retaliation is experienced, could result in a constructive escalation of the correction of wrongdoing.

If organisational trust is truly an expectation of fair treatment and the absence of harm (as per the definition conceptualised earlier), then it should be expected that a whistleblower would not have any reason to fear reporting internally since retaliation would reasonable not be expected. If trust exists, it implies that the organisation shows competence, fairness and integrity. It is an organisation that is open and honest, reliable and true to its word. Furthermore, the organisation will be concerned about the well-being of its employees and will act to protect them. If this is the case, and whistleblowing is effectively dealt with, the organisational responses should increase trust. The contribution of a positive organisational response goes beyond the whistleblowing issue itself it also contributes to establishing a deeper level of trust, possibly moving from calculus-based trust, to knowledge-based trust over a shorter period of time in young relationships. In other words, the response itself could, in turn, strengthen trust relationships, and this could subsequently be to the benefit of the organisation and the whistleblower in cases of reporting. This, in turn, would build further organisational trust as knowledge and experience about such situations would be gained. Therefore, an upward and constructive spiral of internal reporting would likely develop. However, the contradictions of high levels of trust, where identification with the organisation is so strong that it may serve to undermine remedial action, need to be tested in order to establish what effect they will have on reporting.

\section{CONCLUSION}

This is a modest study based on quantitative surveys in a single organisation, but it indicates that the phenomenon of trust deserves academic attention when it comes to understanding the choices of whistleblowers and the harm done to the practice by retaliation against whistleblowers. The harm is not just that wrongdoing remains unaddressed, but that trust is undermined, which may have long-term impacts on the whistleblower and the organisation. Two issues merit further research: First, the paradoxical results of high levels of trust, namely that trust at this level may produce organisational loyalty in conflict with a whistleblower's own ethical sense. This may inhibit whistleblowing. Second, that other factors not related to organisational trust may facilitate the choice to blow the whistle externally. This may mean that internal and external whistleblowing are intrinsically different phenomena and hence correlate differently with organisational trust. Furthermore, it is arguable that trust is a broader concept than merely the fear of reprisal and is also a more useful concept in an organisational setting.

\section{AKNOWLEDGEMENTS:}

I would like to acknowledge and thank Prof. Tina Uys and Dr Neville Bews for their valuable contributions as supervisors for this study, which was conducted for my MA dissertation.

\section{REFERENCES}

Adams, C.A. (2002). Internal organisational factors influencing corporate social and ethical reporting: Beyond current theorising. Accounting, Auditing and Accountability Journal, 15(2), 223-250.
Barnett, T. (1992). A preliminary investigation of the relationship between selected organisational characteristics and external whistleblowing by employees. Journal of Business Ethics, 11(12), 949-959.

Bews, N.F. (1999). A sociological analysis of the concepts 'post-industrial' and 'post-modern' and their effect on the notion of employer-employee trust. Unpublished masters dissertation, Johannesburg: Rand Afrikaans University.

Bews, N.F. (2000). An investigation into the facilitators of the trustworthiness of managers. Unpublished PhD thesis, Johannesburg: Rand Afrikaans University.

Calland, R. \& Dehn, G. (2004). (Eds.) Whistleblowing around the world: Law, culture and practice. Cape Town: ODAC. PCaW.

Camerer, L. (1996). Ethics and the professions: Blowing the whistle on crime. African Quarterly Review, 5(6), 48-54.

Camerer, L. (2001). Protecting whistleblowers in South Africa: The Protected Disclosures Act, no 26 of 2000, Occasional Paper No 47. Retrieved June 29, 2004, from the World Wide Web: http://www.iss.co.za?Pubs?Papers/47/Paper47.html

Claybrook, C. (2004). Viewing organisational trust and internal auditing. Paper presented to the Institute of Internal Auditors Research Foundation, Dallas, U.S.A.

Davis, M. (1989). Avoiding the tragedy of whistleblowing. Business E Professional Ethics Journal, 8(4), 3-19.

Dehn, G. (2001). Whistleblowing: A new perspective. Public concern at work. Retrieved June 29, 2004, from the World Wide Web: http://www.u4.no/document/literature.cfm?key=40

Delahaye Paine, K. (2003). Guidelines for measuring trust in organisations. Institute for Public Relations. Retrieved August 7, 2005, from the World Wide Web: http://www. instituteforpr.com/pdf/2003-measuringtrust.pdf

Gillis, T. (2003). More than a social virtue: public trust among organisations' most valuable assets. Communication World, April-May.

Greenberg, J. \& Baron, R.A. (2003). Behaviour in Organizations. Eighth edition. Prentice Hall: New Jersey.

Gundlach, M.J., Douglas, S.C. \& Martinko, M.J. (2003). The decision to blow the whistle: A social information processing framework. Academy of Management Review, 28(1), 107-123.

Heacock, M.V. \& McGee, G. (1987). Whistleblowing: An Ethical Issue in Organizational and Human Behavior. Business and Professional Ethics Journal, 6(4), 35-46.

Husted, B.W. (1998). The ethical limits of trust in business relations. Business Ethics Quarterly, 8(2), 233-248.

Johnson, R.A. (2003). Whistleblowing: when it works and why. London: Lynne Rienner Publishers London.

Johnson, C.B. \& Wright, C.J. (2004). Make it easy they will come. The Internal Auditor, 61(1), p. 69

Jos, P.H., Tompkins, M.E. \& Hays, S.W. (1989). In praise of difficult people. Public Administration Review, November/ December, 552-561.

King, G. III. (1999). The implications of an organisation's structure on whistleblowing. Journal of Business Ethics, 20, 315-326

Lewicki, R.J. \& Bunker, B.B. (1996). Developing and maintaining trust in work relationships. In Kramer, R.M. \& Tyler, T.R. (Eds.). Trust in organisations: Frontiers of theory and research. Thousand Oaks, Sage: California.

Miceli, M. \& Near, J.P. (1992). Blowing the whistle: The organisational and legal implications for companies and employees. Lexington Books: New York.

Miethe, T.D. 1999. Whistleblowing at Work: Tough Choices In Exposing Fraud, Waste, Abuse On The Job. Westview Press: Colorado.

Milliken, F.J., Morrison, E.W. \& Hewlin, P.F. (2003). An exploratory study of employee silence. Journal of Management Studies, 40(6), 1453-1476.

Mishra, A.K. (1996). Organisational responses to crisis. The centrality of trust. In Kramer, R.M. \& Tyler, T.R. (Eds.). Trust in organisations: Frontiers of theory and research. Thousand Oaks, Sage: California. 
Morehead Dworkin, T.M \& Baucus, M. (1998). Internal vs. external whistleblowers: A comparison of whistleblowing processes. Journal of Business Ethics, 17, 1281-1298.

PriceWaterhouseCoopers. (2005). PriceWaterhouseCoopers global economic crime survey. Retrieved on December 01, 2005, from the World Wide Web: http://www.pwcglobal.com/extweb/ insights.nsf/docid/D1A0A616149F2806852570C0006716C0

Rothschild, J. \& Miethe, T.D. (1994). "Whistleblowing as resistance in modern work organizations: the politics of revealing organizational deception and abuse" in Jermier, J.M., Knights, D., \& Nord, W.R. 1994. Resistance and Power in Organizations. Routledge: London.
Shockley-Zalabak, P., Ellis, K., \& Cesaria, R. (2003). More than a social virtue: Public trust among organisations' most valuable assets. Communication World, (20) Apr/May, 10-11.

Sztompka, P. (1999). Trust: A sociological theory. Cambridge University Press: Cambridge.

Trevino, L.K. \& Bart, V. (1999). Peer reporting of unethical behaviour: Social context perspective. Academy of Management Journal, 35(1), 38-65.

Uys, T. (2000a). Hero or traitor? The professional person as whistleblower. Paper presented at IRR Conference, Durban, South Africa.

Uys, T. (2000b). The Politicisation of whistleblowers: a case study. Blackwell Publishers Ltd, 9(4), 259-287.

Uys, T. (2005). Betrayal, loyalty and trust. Paper presented at the 37th World Congress of the International Institute of Sociology, Stockholm, Sweden.

Uys, T. \& Senekal, A. (2005). Morality of principle versus morality of loyalty: The case of whistleblowing. Paper presented at the 5th Annual Conference of Ben-Africa, Kasane, Botswana. 